\title{
Amplification of Mdmx and overexpression of MDM2 contribute to mammary carcinogenesis by substituting for $\mathrm{p} 53$ mutations
}

\author{
Qiong $\mathrm{Yu}^{1+}$, Yan $\mathrm{Li}^{2+}$, Kun $\mathrm{Mu}^{1}$, Zhishuang $\mathrm{Li}^{1}$, Qingyong Meng ${ }^{3}$, Xiaojuan $\mathrm{Wu}^{1}$, Yan Wang ${ }^{1}$ and $\mathrm{Li}^{\mathrm{Li}}{ }^{*}$
}

\begin{abstract}
Background: The p53 tumor suppressor gene is mutated or deleted in nearly half of human cancers. The murine double minute 2 (Mdm2) and $M d m x$ represent two important cellular regulators of $\mathrm{p} 53$. The aim of this study was to evaluate the abnormalities of p53, Mdmx and Mdm2 genes in archived breast cancers.

Methods: We assessed the genetic instability at p53, Mdmx and Mdm2 using high resolution multi-color fluorescent in situ hybridization (FISH) protocol and detected the expression status of the tumor protein p53 (TP53), MDMx and MDM2 by immunohistochemistry in 115 archived samples of infiltrating ductal breast carcinomas with foci of ductal carcinoma in situ (DCIS) components.

Results: The presence of p53 allelic loss and/or TP53 overexpression was observed in 38\% out of all patients, and was significantly more often in larger, high grade, ER negative and high ki67 tumors. Mdmx amplification with low-level increase of gene copy number is at high frequency while Mdm2 amplification is rare in primary breast cancer. Mdmx amplification was seen in more invasive carcinomas than preinvasive lesions. MDMx and MDM2 overexpression were detected in $65 \%$ and $38 \%$ of all cases respectively. Moreover it was showed that most tumors contained either p53 dysfunction or Mdm2 alteration, but not both. This distribution was significant $(P<0.05)$. Inverse correlation between Mdmx amplification/overexpression and p53 disfunction was also observed $(P<0.05)$.
\end{abstract}

Conclusions: Our results suggest the involvement of $\mathrm{Mdm} 2$ and $\mathrm{Mdmx}$ in $\mathrm{p} 53$-independent breast carcinogenesis and Mdmx may contribute to the regulation of p53 independently of Mdm2.

Virtual slides: The virtual slides for this article can be found here: http://www.diagnosticpathology.diagnomx.eu/vs/ 1450529994118798.

Keywords: Breast cancer, p53, Mdmx, Mdm2, FISH

\section{Background}

The p53 tumor suppressor gene has a central role in maintaining the integrity of the genome and the defense against cancer. The tumor protein 53 (TP53) becomes stabilized and regulates numerous downstream targets to induce cell cycle arrest, senescence, apoptosis, and DNA repair in response to diverse stresses. Mutation and $\mathrm{LOH}$ at the p53 locus occur as tumors progress under conditions of increasing genomic instability [1-3]. p53 is mutated in

\footnotetext{
*Correspondence: lillie6636@sdu.edu.cn

${ }^{\dagger}$ Equal contributors

'Department of Pathology, Shandong University School of Medicine, 44\#, Wenhua Xi Road, 250012 Jinan, Shandong, PR. China

Full list of author information is available at the end of the article
}

nearly half of all human cancers, and it is functionally abrogated in much of the remaining $50 \%$ of cancers through signaling pathways [4]. In breast cancer, approximately about $15 \%$ to $50 \%$ of the cases carry a mutant p53 gene and/or loss of heterozygosity (LOH) at chromosome location 17p13, where the p53 gene is located [5-7].

TP53 is negatively regulated by numerous factors. The murine double minute $2(\mathrm{Mdm} 2)$ and $\mathrm{Mdmx}$ represent two important cellular regulators of p53. The Mdm2 gene was identified as one of three unknown genes (Mdm1-3) coamplified in the spontaneously transformed 3T3-DM mouse cell line [8]. Acting as an ubiquitin (Ub) protein ligase (E3), MDM2 (also called HDM2) can bind and ubiquitinate TP53 and promote rapid degradation of TP53 
through the ubiquitin proteolysis pathway, which keeps TP53 at low levels in the absence of stress signals. MDM2 overexpression has been observed in about a third of human sarcomas that retained wild-type TP53 [3,9-11].

MDMx (also known as MDM4), a TP53 binding protein structurally homologous to MDM2, was more recently identified [12]. MDMx was found amplified or overexpressed in $10-20 \%$ of breast cancers, glioblastomas, retinoblastomas, and soft tissue sarcomas [3,13-15] in the presence of wild-type TP53, which confirmed that aberrant expression of MDMx may contribute to tumor formation by inhibiting TP53 activity. But the molecular details of the role of MDMx in the control of P53 and tumorigenesis are not well understood.

Although MDM2 and MDMx are overexpressed in many malignancies, data were mainly from cell-based studies and in vivo studies on mouse models. Limited studies using human archived tissue of breast cancers revealed the roles of the above molecular markers in carcinogenesis and the relationship among them as well as the relationship with the clinicopathologic characteristics. And to our knowledge, there was no study on these molecular markers using invasive carcinoma and carcinoma in situ in the same tumors. In present study our aims were to assess the genetic instability at p53 (located on 17p13.1), Mdmx (located on 1q32.1) and Mdm2 (located on 12q15) and address the roles of these proteins in breast cancer progression. Using multi-color fluorescence in situ hybridization (FISH) protocols in 115 primary breast cancers, we examined the genetic changes at p53, Mdmx and Mdm2 loci in archived breast cancers. The expression of these proteins was evaluated by immunohistochemistry.

\section{Materials and methods}

\section{Patients and tumor characteristics}

One hundred and thirty seven primary invasive breast carcinoma samples with foci of ductal carcinoma in situ (DCIS) were collected from 137 women undergoing surgery between January 2007 and September 2008 in Qilu Hospital of Shandong University, Jinan, China. The study was approved by the Ethics Committee of Shandong University. The tumor samples were fixed in $4 \%$ phosphate buffered formaldehyde directly after the operation and paraffin embedded. From each specimen ten contiguous sections were prepared and used for hematoxylin and eosin staining, immunohistochemistry and FISH procedure (thickness $4 \mu \mathrm{m}$ ). Reliable immunohistochemistry staining could be obtained from 129 of these tumors and goodquality DNA was available for hybridization of 121 of the 137 tumors. Out of 137 tumors initially selected 22 tumors were excluded for subsequent analysis.

For each tumor, malignancy grade, tumor size (diameter), lymphnode status at the time of diagnosis were evaluated. All tumors were diagnosed according to World
Health Organization criteria [16] and graded based on the recommendations of Elson and Ellis.

\section{Immunohistochemistry}

Immunohistochemistry was carried out as described previously [17]. The antibodies against ER (Clone 1D5, DAKO), PR (Clone PgR 636, DAKO), Ki67 (Clone MIB-1, DAKO), HER-2 (4B5, Ventana), p53 (DO-1, Santa Cruz), MDM2 (SMP14, Santa Cruz), MDMx (ab76362, abcam) were applied at dilution 1:100, 1:100, 1:1000, 1:100, 1:200 and 1:800. A positive section produced in preliminary experiments was used as a positive control. Normal fetus serum was used as a negative control by replacement of the relevant primary antibody.

Only distinct nuclear staining was accepted as positive reactions for ER, PR, p53 and ki67, whereas HER-2 showed a membrane staining. It was scored positive for ER or PR if $>=1 \%$ of the nuclei of neoplastic cells showed definitive staining. HER-2 was evaluated according to ASCO/CAP guideline proposed for the evaluation of HER2 testing: a $3+$ score or a $2+$ score with FISH ratio of more than 2.2 was considered to indicate positive HER2 expression. Only tumor tissues with diffuse strong nuclear staining for TP53 was considered to show mutant p53 while scattered weak to moderate nuclear staining was scored negative $[18,19]$. Ki67 status was scored low if $<15 \%$ of the nuclei of neoplastic cells were positive, and high if $>=15 \%$ of the nuclei of neoplastic cells were positive [20]. All tumor cells with nuclear staining or simultaneous nuclear and cytoplasmic staining were regarded as positive for MDM2 and MDMx. The degree of staining of tumor cells was categorized as -, negative; +, weak; ++, moderate; and +++ , strong. Normal breast tissues were included as the controls.

\section{FISH procedure}

High resolution multi-color FISH was performed to detect gene copy number changes of p53, Mdmx and $\mathrm{Mdm} 2$ in all 115 cases. All probes were obtained from Professor Anders Zetterberg, Cancer Center Karolinska, Sweden, and labeled with Spectrum Green, Spectrum Orange or Texas Red. Sections were removed excess wax followed by dehydration in absolute alcohol. Antigenic recovery was performed through incubating the slides for 1 hour at $80^{\circ} \mathrm{C}$ in $0.1 \mathrm{M}$ citrate buffer ( $\mathrm{pH}$ 6.0). A 10-minute digestion with pepsin $(1 \mathrm{mg} / \mathrm{ml}$ in $0.01 \mathrm{M} \mathrm{HCL})$ was performed followed by fixation in $1 \% \mathrm{PF}$. The probes were dissolved in the hybridization mixture. Denaturation of probes and target DNA were performed simultaneously at $90^{\circ} \mathrm{C}$ for $10 \mathrm{~min}$ and each slide was incubated in a moist chamber for hybridization at $47^{\circ} \mathrm{C}$ overnight. After hybridization, slides were washed in $4 \times \operatorname{SSPE}$ for $10 \mathrm{~min}$ at $37^{\circ} \mathrm{C}$ and $47^{\circ} \mathrm{C}$ respectively. Nuclei were mounted and counterstained with 4',6-diamino-2-phenylindole (DAPI, Vectashield). 


\section{Signal scoring and evaluation}

Signal evaluation was carried out using an Axioplan 2 microscope (Carl Zeiss AB, Sweden) mounted with a charge-coupled device (CCD) camera Axiocam MRM (Carl Zeiss $A B)$, coupled with a computer with Axio Vision software (Carl Zeiss $A B)$. Only signals in the tumor areas based on both a consecutive section stained by hematoxylin and eosin and DAPI morphology were counted and evaluated. Two researchers (Yu\&Li) carried out all investigations independently. In cases of discordance, the results would be evaluated by the third observer ( $\mathrm{Li} \mathrm{Li}$ ) and the result which two observers supported would be taken.

The exact copy number of the signals per nucleus was recorded, and at least 100 non-overlapping nuclei per sample were analyzed. More than $30 \%$ of counted nuclei with the number of signals less than those of corresponding chromosomes defined those samples containing gene deletion. Gene amplification was defined by the presence of an excess in the number of gene loci over the number of corresponding chromosomes on more than $20 \%$ of counted cells [21]. The chromosome 1,12,17 centromericprobe was used as internal controls.

\section{Statistic analysis}

Statistical analyses were performed using the SPSS for Windows version 16.0. The correlations between variables were performed using Fisher's exact test or Spearsman rank correlation test. All tests were two-sided with significance level $\alpha$ set to 0.05 .

\section{Results}

\section{Characteristics of patients}

The patients were all female and their ages at the time of the diagnosis ranged from 23 to 85 years (mean 49 years). The tumor size ranged from 0.6 to $11 \mathrm{~cm}$ in the greatest dimension (mean $2.8 \mathrm{~cm}$ ). Patients and tumor characteristics of 115 cases are summarized in Table 1.

\section{Genetic instability in primary breast cancer}

Mdmx and Mdm2 amplification and p53 deletion were identified by multi-color FISH. As shown in Table 1, among the 115 breast cancers amplification of Mdmx was found in 65 cases $(56.5 \%)$ of cases, higher than published studies [15]. But only low-level increase of gene copy number $(<10$ copies) was observed in all samples (Figure 1A). Amplification of Mdm2 was identified only in two of these samples (1.7\%) indicating that Mdm2 amplification is uncommon in primary breast cancers. Allelic loss of p53 was detected in 28/115 (24.3\%) of cases (Figure 1B). The frequency of Mdmx and/or p53 genetic abnormality was up to $70 \%$ (81/115), which indicated most tumors showed either p53 or Mdmx genetic abnormalities. No significant correlation was observed between p53 deletions and Mdmx amplification (Table 2).
We compared gene copy number changes between DCIS and invasive areas, and found 56 cases showed Mdmx amplification in both DCIS and invasive areas and 9 cases were observed Mdmx amplification only in infiltrating areas but not in the DCIS components (Figure 2). p53 deletion was found in from in situ to invasive disease for all of the gene loss cases thus supporting earlier findings that p53 abnormality has a role early in the pathogenesis of breast lesions.

The expression status of TP53, MDMx and MDM2 proteins We analyzed TP53, MDMx and MDM2 proteins levels in formalin-fixed tissues of all 115 breast cancer samples using an immunohistochemical approach. In total, 20 tumors (17.3\%) showed diffuse strong staining for TP53 (Figure 3A). 75 tumor (65.2\%) showed MDMx diffuse strong staining (scored +++ ) (Figure $3 \mathrm{~B}$ ), which correlated with Mdmx amplification ( $\mathrm{p}<0.01)$. Herein, MDMx overexpression was recognized as diffuse strong staining (scored +++ ). MDM2 overexpression was detected in 44 out of 115 cases (38.3\%) (Figure 3B). Both cytoplasmic and nuclear compartments were stained with MDMx and MDM2.

\section{Dysfunction of $\mathrm{p} 53$ in relation to $\mathrm{Mdmx}$ amplification and MDM2 overexpression}

The p53 dysfunctional genophenotype was identified in individual tumors by the presence of LOH of p53 by FISH, p53 protein overexpression by immunohistochemistry, or both. Totally, the presence of LOH of p53 and/or TP53 overexpression was observed in 44 tumors (38.3\%) out of all patients. $\mathrm{LOH}$ of p53 and its overexpression were each present in around $20 \%$ of the cases implying p53 mutations and allelic loss contributed p53 dysfunction equally in this group. They were observed in the same tumor in 4 cases supporting the findings by others that mutation of one p53 allele could be accompanied by loss of the complementary wild type allele [22]. There was inverse correlation between p53 abnormality and MDM2 overexpression $(P<0.05)$. We also found inverse correlation between p53 abnormality and amplification/overexpression of $\operatorname{Mdmx}(P<0.05)$.

\section{Abnormalities of $\mathrm{p53}, \mathrm{Mdmx}$ and $\mathrm{Mdm} 2$ in relation to tumor clinicopathologic characteristics}

The dysfunctional p53 phenotype was found to be linked with tumor size $(P<0.05)$ and tumor grade $(P<0.01)$. In addition, tumors with dysfunctional p53 preferentially had negative ER status $(P<0.05)$ and high ki67 index $(P<0.01)$. But Mdmx amplification or MDM2 overexpression was not found to be correlated with any of the above clinicopathologic tumor characteristics. A detailed summary of the data is summarized in Table 1. 
Table 1 Alterations of $M d m x, M d m 2$ and p53 in 115 primary breast cancers

\begin{tabular}{|c|c|c|c|c|c|c|c|}
\hline \multirow[t]{2}{*}{ Characteristics } & \multirow[t]{2}{*}{ Patients no. (\%) } & \multicolumn{2}{|c|}{ Mdmx amplification } & \multicolumn{2}{|c|}{ Mdm2 overexpression } & \multicolumn{2}{|c|}{ p53 disfunction } \\
\hline & & no. (\%) & $P$ & no. (\%) & $P$ & no. (\%) & $P$ \\
\hline Tumor size $^{1}$ & $36(31.3 \%)$ & $22(61.1 \%)$ & & $19(41.3 \%)$ & & $8(22.2 \%)$ & \\
\hline $\mathrm{d} \leqq 20 \mathrm{~mm}$ & $66(57.4 \%)$ & $35(53.0 \%)$ & 0.710 & $21(31.8 \%)$ & 0.301 & $29(47.5 \%)$ & 0.009 \\
\hline $50 \mathrm{~mm}>=d>20 \mathrm{~mm}$ & $13(11.3 \%)$ & $8(61.5 \%)$ & & $4(30.8 \%)$ & & $7(53.8 \%)$ & \\
\hline \multicolumn{8}{|l|}{$\mathrm{d}>50 \mathrm{~mm}$} \\
\hline \multicolumn{8}{|l|}{ Grade } \\
\hline 1 & $9(7.8 \%)$ & 7 (77.8\%) & & $5(55.6 \%)$ & & $0(0)$ & \\
\hline$\|$ & $67(58.3 \%)$ & $38(56.7 \%)$ & 0.244 & $22(32.8 \%)$ & 0.738 & $22(32.8)$ & 0.001 \\
\hline III & 39 (33.9\%) & $20(51.3 \%)$ & & $17(43.6 \%)$ & & $22(56.4 \%)$ & \\
\hline \multicolumn{8}{|l|}{ Nodal status $^{2}$} \\
\hline $\mathrm{N}$ & $51(44.3 \%)$ & $31(60.8 \%)$ & 0.453 & $24(47.1 \%)$ & 0.122 & $18(35.3 \%)$ & 0.348 \\
\hline $\mathrm{N}+$ & $64(55.7 \%)$ & $34(53.1 \%)$ & & $20(31.2 \%)$ & & $26(40.6 \%)$ & \\
\hline \multicolumn{8}{|l|}{ ER status } \\
\hline Negative & $42(36.5 \%)$ & $24(57.1 \%)$ & 1.000 & $12(28.6 \%)$ & 0.116 & $22(52.4 \%)$ & 0.016 \\
\hline Positive & $73(63.5 \%)$ & $41(56.2 \%)$ & & $32(43.8 \%)$ & & $22(30.1 \%)$ & \\
\hline PR status & 4 & & & & & & \\
\hline Negative & $5(39.1 \%)$ & $22(48.9 \%)$ & 0.248 & $14(31.1 \%)$ & 0.241 & $20(44.4 \%)$ & 0.185 \\
\hline Positive & $70(60.9 \%)$ & $43(61.4 \%)$ & & $30(42.9 \%)$ & & $24(34.3 \%)$ & \\
\hline \multicolumn{8}{|l|}{ HER-2 status } \\
\hline Negative & $93(80.9 \%)$ & $54(58.1 \%)$ & 0.633 & $38(40.9 \%)$ & 0.330 & $37(40.7 \%)$ & 0.305 \\
\hline Positive & $22(19.1 \%)$ & $11(50.0 \%)$ & & $6(27.3 \%)$ & & $7(31.8 \%)$ & \\
\hline \multicolumn{8}{|l|}{ Ki67 expression } \\
\hline Low & 44 (38.3\%) & $28(63.6 \%)$ & 0.251 & $17(38.6 \%)$ & 1.000 & $10(22.7 \%)$ & 0.006 \\
\hline High & 71 (61.7\%) & $37(52.1 \%)$ & & $27(38.0 \%)$ & & $34(47.9 \%)$ & \\
\hline \multicolumn{8}{|l|}{ Mdmx amplification } \\
\hline Yes & 65 (56.5\%) & & & 21 & 0.176 & 19 & 0.033 \\
\hline No & $50(43.5 \%)$ & & & 23 & & 25 & \\
\hline \multicolumn{8}{|l|}{ Mdm2 overexpression } \\
\hline Yes & 44 (38.3\%) & - & - & - & - & 11 & 0.018 \\
\hline No & 71 (98.3\%) & & & & & 33 & \\
\hline
\end{tabular}

\section{Discussion}

Breast cancer is characterized by a number of genetic aberrations [23-25]. Although improvements have been achieved in recent years, few genetic biomarkers are available to easily identify individuals at risk for breast cancer or breast cancer progression [26-28]. A better understanding of the molecular mechanisms involved in breast cancer initiation and progression will likely contribute to providing useful prognostic biomarker and therapeutic target for breast cancer therapy.

FISH is considered to be the most precise method for amplification and deletion detection. In this study, we successfully detected the gene copy number changes of p53, Mdmx and Mdm2 by multi-color FISH, which enables investigators obtaining far more information from one specific cell at one time, rather than carrying out separate experiments on multiple specimens prepared from the same sample, then extrapolating results.

Dysfunction of p53 often occurs as a result of mis-sense mutation, but can also result from nonsense or deletion mutation [3]. TP53 is a product of the mutated gene. Therefore here TP53 overexpression using immunohistochemical method was adopted to investigate p53 mutation. For scattered weak to moderate staining can be observed in normal breast tissue, hyperplasia breast tissue and tumor tissue without p53 mutation, only tumor tissues with diffuse strong nuclear staining for TP53 was considered to show mutant p53 as in serious papillary 

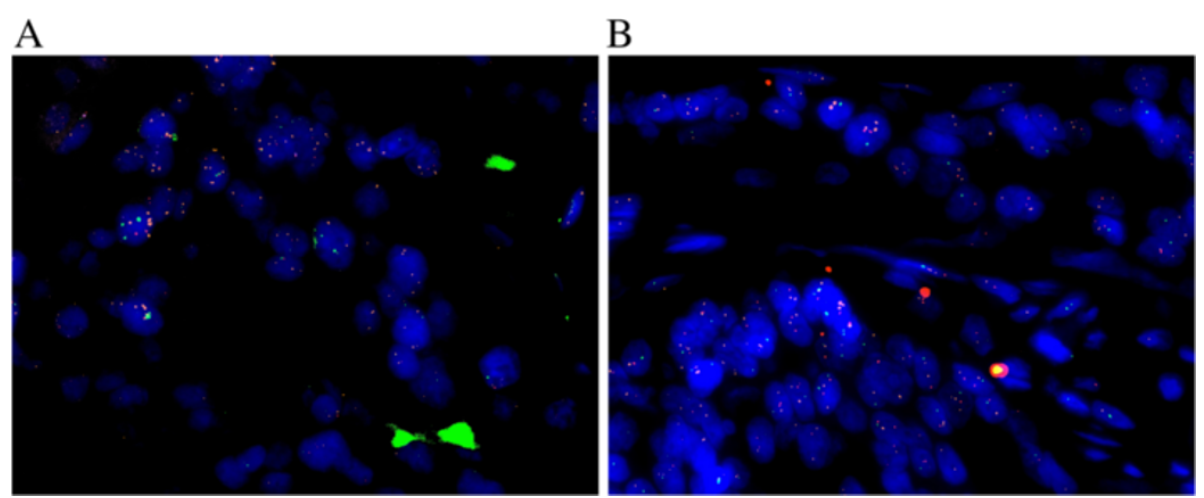

Figure 1 Genetic abnormalities detected by multi-color FISH in primary breast cancer. p53, Mdmx and Mdm2 were labeled with green, orange and red respectively (A) Low level of Mdmx amplification accompanied with normal gene copy number of p53 and Mdm2 is shown, most cancer cell nuclei have $<10$ orange signals $(F I S H, x 630)$. (B) The tumor cells lack of gene number changes of Mdmx and Mdm2 show LOH of p53, most cancer cell nuclei have only 1 green signal $(\mathrm{FISH}, \times 630)$.

carcinoma in ovary. In this study, FISH was adopted to detect p53 allelic loss as a co-criterion for identifying the dysfunctional p53 phenotype. Allelic loss of p53 was detected in $23 \%$ of all analyzed samples in present study while $17 \%$ of cases showed TP53 overexpression indicating p53 mutation. The presence of p53 allelic loss and/or TP53 overexpression was observed in $38 \%$ out of all patients, within the range of frequencies reported by others $[29,30]$. Because of the involvement of DCIS, p53 alteration must be an early event in breast carcinogenesis. According to previous reports, mutation of p53 is associated with increased tumor size and tumor grade, axillary lymph node metastases and ki67 expression [30-32]. But data presented here indicate there was no significant relationship between p53 allelic loss or TP53 overexpression and tumor node status, whereas p53 dysfunction was detected significantly more often in larger $(\mathrm{d}>20 \mathrm{~mm})$, high grade (grade 3), ER negative and high ki67 index tumors.

$\mathrm{LOH}$ and mutation of p53 only present in part of breast cancers. It is believed that tumors retaining wild type p53 contain abnormalities in other genes that interact with p53 or are downstream of p53 and result in an identical physiological defect within the cells. One of the best examples of the latter class is amplification or overexpression of Mdm2, which was observed in a subset of human tumors, some of which retain wild-type p53 [33] leading to the conclusion that increased levels of MDM2 directly contribute to human tumor formation

Table 2 Association analyses of Mdmx, Mdm2 and p53 genetic changes in primary breast cancers

\begin{tabular}{lcccccccc}
\hline & \multicolumn{3}{c}{ Mdmx amplification } & & \multicolumn{3}{c}{ Mdm2 amplification } \\
\cline { 2 - 3 } & Yes & No & $\boldsymbol{P}$ & & Yes & No & $\boldsymbol{P}$ \\
\hline p53 deletion & 12 & 16 & $<0.125$ & & 0 & 28 & 1.000 \\
Yes & 53 & 34 & & & 2 & 85 & \\
No & & & & & & &
\end{tabular}

by substituting for mutations in p53 gene, which represents an alternative mechanism by which tumor cells escape from the tumor suppressive activities of p53. Overexpression of MDM2 can impair wild-type TP53 function in two ways by binding to the transactivation site of TP53 in the nucleus or by targeting TP53 for ubiquitination and degradation in the cytoplasm, and linked with low levels of TP53 immunostaining in human breast cancers [34]. Frequent overexpression of MDM2 in advanced breast tumors was observed [34]. It was reported MDM2 protein overexpression often due to gene amplifications [35,36]. But Mdm2 amplification was found only in two samples while its overexpression was observed in $38 \%$ of all tumors in this study, which supported Mdm2 amplification occurs at a lower frequency than increased transcription or enhanced translation in breast cancers. So in this study MDM2 overexpression was used to reflect Mdm2 abnormality. Importantly, we found most tumors contained either a TP53 alteration or a MDM2 alteration, but not both. This distribution was significant $(P<0.05)$, and strongly suggests alterations of these two genes are mutually exclusive. Our data support the hypothesis that the major effect of MDM2 overexpression is identical to that resulting from p53 mutation. One would expect that either TP53 or MDM2 would be altered and alterations of both genes should be examined in a given breast cancer. There were few tumors observed without TP53 dysfunction and MDM2 overexpression in this study. So there might be other alterations of TP53 or MDM2, or some of these tumors might progress through genetic events that involve a totally different pathway. More detailed analyses of such tumors are needed to reveal.

Several studies together now also implicate aberrant expression of MDMx could thus contribute to tumor formation [37]. Unlike MDM2, MDMx does not have intrinsic E3 ligase activity and does not promote TP53 degradation. 

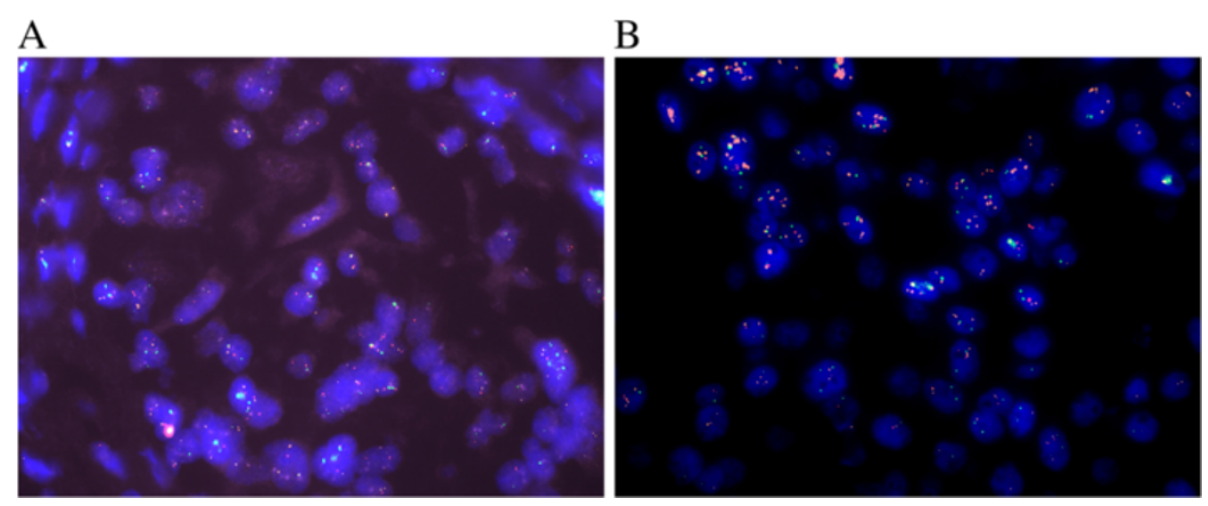

Figure 2 Mdmx amplification in the infiltrating components (A) but not in the DCIS (B) (FISH, $\times 630$ ).

However, MDMx binds TP53 in its transactivation domain and is thereby able to inhibit its transcriptional activity. Amplification of Mdmx was found in several tumor types. Migliorini found amplification of Mdmx correlated with a wild-type p53 status and lack of Mdm2 amplification [38]. In this study Mdmx was amplified in $57 \%$ of all cases, while it was overexpressed in $65 \%$ of all tumors, indicating MDMx overexpression was mainly due to its amplification. Mdmx amplification was adopted in data analyses. Although not all the tumors with Mdmx amplification show wild type $\mathrm{p} 53$, significant inverse correlation between Mdmx amplification and TP53 overexpression was still observed. We did not find correlation between Mdmx amplification and MDM2 overexpression, but tumors with Mdmx amplification were more likely lack of MDM2 overexpression. Up to now, it was still controversial whether each plays its own distinct role or MDM2 and MDMx function together as one heterocomplex in p53 regulation. Our data seems to support MDMx may contribute to the regulation of TP53 independently of MDM2. A recent

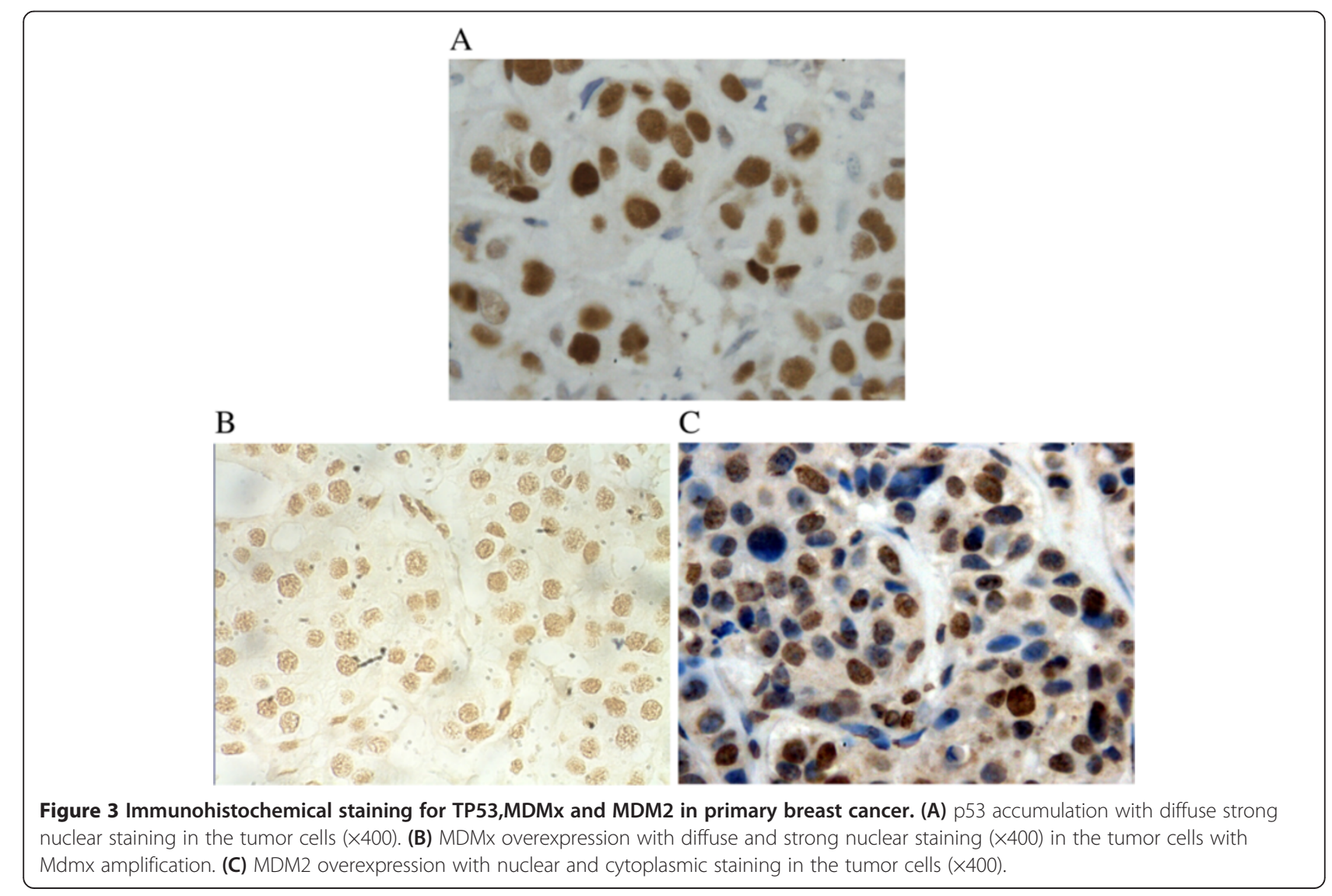


evidence demonstrated that endogenous level of MDMx could regulate transformation and chromosomal stability in TP53-deficient cells and these MDMx functions were not shared by MDM2, and were distinct from the wellestablished ability of MDMx to complex with and inhibit TP53 activity [39]. Together these data strongly indicate that Mdmx amplification is a common event in breast carcinogenesis, even in most tumorigenesis and MDMx probably functions as an oncogene through a quite different way compared to MDM2. The molecular mechanism that prevents TP53 activation and carcinogenesis in the presence of high level of MDMx is largely unknown, which need to be elucidated in the future. Furthermore we found Mdmx amplification was seen in more invasive breast cancers. So we speculate amplified Mdmx more likely to be associated with tumor progression. Larger sample sizes to provide more definitive data on the potential role of genetic changes of Mdmx in breast cancer progression should be performed in the future.

\section{Conclusions}

In conclusion, we detected genetic alterations of p53, Mdmx and Mdm2 by multi-color FISH in one specific cell simultaneously and compared these genetic alterations in DCIS and invasive lesions in individual cases for the first time. Our data indicate that disruption of the TP53 pathway by high levels of MDM2 and MDMx are common events in the breast tumorigenesis and $\mathrm{Mdmx}$ amplifies quite frequently with low-level increase of gene copy number while few tumors with Mdm2 amplification are seen in primary breast cancers. Mdmx amplification is seen in invasive breast cancer but not in DCIS in some cases and likely to be associated with tumor progression. Moreover, high levels of both genes in breast cancer that retain wild-type p53 suggest that these inhibitors may substitute for mutations in p53, therefore, contribute to the severity and progression of the disease. But as an oncogene, high level of MDMx may act through a quite different way compared to MDM2. Together, our data strongly suggest that overexpression of MDM2 or MDMx and p53 mutations in primary breast cancer are mutually exclusive events. The presence of high levels of MDM2 and MDMx in many breast cancers suggests that these data should be considered in the treatment of breast cancer.

\section{Competing interests}

We declare that we have no conflict of interests.

\section{Authors' contributions}

LL designed the study, carried out the experiments and drafted the manuscript; QY, YL, ZSL, KM carried out the FISH detection. XJW and YW performed immunohistochemical interpretation of the tumor tissue. QYM participated in the statistical analysis. All authors read and approved the final manuscript.

\section{Acknowledgments}

We thank Dr. Anders Zetterberg from Cancer Center Karolinska, Sweden for providing the probes and instruction with FISH technique. This work was supported by the Grants from National Natural Science Foundation of China (no. 30901456 and no. 81272902).

\section{Author details}

'Department of Pathology, Shandong University School of Medicine, 44\#, Wenhua Xi Road, 250012 Jinan, Shandong, PR. China. ${ }^{2}$ Department of Medical Oncology, Shandong Cancer Hospital and Institute, Jinan University, 250117 Jinan, Shandong, PR. China. ${ }^{3}$ The No.2 People's Hospital of Jinan, 148\#, Jingyi Road, 250001 Jinan, Shandong, People's Republic of China.

Received: 16 January 2014 Accepted: 18 March 2014

Published: 25 March 2014

\section{References}

1. Harris SL, Levine AJ: The p53 pathway: positive and negative feedback loops. Oncogene 2005, 24:2899-2908.

2. Liu G, Chen X: Regulation of the p53 transcriptional activity. J Cell Biochem 2006, 97:448-458.

3. Wade M, Li YC, Wahl GM: MDM2, MDMX and p53 in oncogenesis and cancer therapy. Nat Rev Cancer 2013, 13:83-96.

4. Shadfan M, Lopez-Pajares V, Yuan ZM: MDM2 And MDMX: alone and together in regulation of p53. Transl Cancer Res 2012, 1:88-89.

5. Deng G, Chen LC, Schott DR, Thor A, Bhargava V, Ljung BM, Chew K, Smith HS: Loss of heterozygosity and p53 gene mutations in breast cancer. Cancer Res 1994, 54:499-505.

6. Pei $D$, Zhang $Y$, Zheng J: Regulation of $\mathrm{p} 53$ : a collaboration between Mdm2 and Mdmx. Oncotarget 2012, 23:228-235.

7. Done SJ, Arneson CR, Ozçelik H, Redston M, Andrulis IL: P53 protein accumulation in non-invasive lesions surrounding p53 mutation positive invasive breast cancers. Breast Cancer Res Treat 2011, 65:111-118.

8. Cahilly-Snyder L, Yang-Feng T, Francke U, George DL: Molecular analysis and chromosomal mapping of amplified genes isolated from a transformed mouse 3T3 cell line. Somat Cell Mol Genet1 1987, 3:235-244.

9. Momand J, Jung D, Wilczynski S, Niland J: The MDM2 gene amplification database. Nucleic Acids Res 1998, 26:3453-3459.

10. Oliner JD, Kinzler KW, Meltzer PS, George DL, Vogelstein B: Amplification of a gene encoding a p53-associated protein in human sarcomas. Nature 1992, 358:80-83.

11. Veerakumarasivam A, Scott HE, Chin SF, Warren A, Wallard MJ, Grimmer D, Ichimura K, Caldas C, Collins VP, Neal DE, Kelly JD: High-resolution arraybased comparative genomic hybridization of bladder cancers identifies mouse double minute 4 (MDM4) as an amplification target exclusive of MDM2 and TP53. Clin Cancer Res 2008, 14:2527-2534.

12. Shvarts A, Bazuine M, Dekker P, Ramos YF, Steegenga WT, Merckx G, van Ham RC, van der Houven van Oordt W, van der EbA J, Jochemsen AG: Isolation and identification of the human homolog of a new p53-binding protein, Mdmx. Genomics 1997, 43:34-42.

13. Laurie NA, Donovan SL, Shih CS, Zhang J, Mills N, Fuller C, Teunisse A, Lam S, Ramos Y, Mohan A, Johnson D, Wilson M, Rodriguez-Galindo C, Quarto M, Francoz S, Mendrysa SM, Guy RK, Marine JC, Jochemsen AG, Dyer MA: Inactivation of the p53 pathway in retinoblastoma. Nature 2006, 444:61-66.

14. Riemenschneider MJ, Buschges R, Wolter M, Reifenberger J, Bostrom J, Kraus JA Schlegel U, Reifenberger GH: Amplification and overexpression of the MDM4 (MDMX) gene from 1q32 in a subset of malignant gliomas without TP53 mutation or MDM2 amplification. Cancer Res 1999, 59:6091-6096.

15. Danovi D, Meulmeester E, Pasini D, Migliorini D, Capra M, Frenk R, de Graaf P, Francoz S, Gasparini P, Gobbi A, Helin K, Pelicci PG, Joechemsen AG, Marine JC: Amplification of Mdmx (or Mdm4) directly contributes to tumor formation by inhibiting p53 tumor suppressor activity. Mol Cell Biol 2004, 24:5835-5843.

16. Lakhani SR, Ellis IO, Schnitt SJ, Tan PH, van de Vijver MJ: WHO classification of tumors of the breast. 4th edition. Lyon: IARC Press; 2012:33-38.

17. Li L, Mu K, Zhou G, Lan L, Auer G, Zetterberg A: Genomic instability and proliferative activity as risk factors for distant metastases in breast cancer. Br J Cancer 2008, 99:513-519.

18. Kikuchi S, Nishimura R, Osako T, Okumura Y, Nishiyama Y, Toyozumi Y, Arima N: Definition of p53 overexpression and its association with the clinicopathological features in luminal/HER2-negative breast cancer. Anticancer Res 2013, 33:3891-3897.

19. Alsner J, Jensen V, Kyndi M, Offersen BV, Vu P, Børresen-Dale AL, Overgaard $J A$ : Comparison between p53 accumulation determined by 
immunohistochemistry and TP53 mutations as prognostic variables in tumours from breast cancer patients. Acta Oncol 2008, 47:600-607.

20. Ahlin C, Aaltonen K, Amini RM, Nevanlinna H, Fjallskog ML, Blomqvist C: Ki67 and cyclin A as prognostic factors in early breast cancer. What are the optimal cut-off values? Histopathology 2007, 51:491-498.

21. Matsuyama H, Pan Y, Mahdy EA, Malmstrom PU, Hedrum A, Uhlen M, Busch C, Hirano T, Auer G, Tribukait B, Naito K, Lichter P, Ekman P, Bergerheim US: p53 deletion as a genetic marker in urothelial tumor by fluorescence in situ hybridization. Cancer Res 1994, 54:6057-6060.

22. Levine AJ, Momand J, Finlay CAM: The p53 tumour suppressor gene. Nature 1991, 351:453-456.

23. Preat F, Simon P, Noel JC: Differences in breast carcinoma immunohistochemical subtypes between immigrant Arab and European women. Diagn Pathol 2014, 9:26-30.

24. Guo L, Meng J, Yilamu D, Jakulin A, Fu M, Wang B, Abulajiang G Significance of ER $\beta$ expression in different molecular subtypes of breast cancer. Diagn Pathol 2014, 9:20-25.

25. Zhang Q, Zhang Q, Cong H, Zhang X: The ectopic expression of BRCA1 is associated with genesis, progression, and prognosis of breast cancer in young patients. Diagn Pathol 2012, 7:181-187.

26. Cheng H, Qin Y, Fan H, Su P, Zhang X, Zhang H, Zhou G: Overexpression of CARM1 in breast cancer is correlated with poorly characterized clinicopathologic parameters and molecular subtypes. Diagn Pathol 2013, 8:129-137.

27. Liu L, Liu Z, Qu S, Zheng Z, Liu Y, Xie X, Song F: Small breast epithelial mucin tumor tissue expression is associated with increased risk of recurrence and death in triple-negative breast cancer patients. Diagn Pathol 2013, 8:71-80.

28. Wang S, Li H, Wang J, Wang D: Expression of microRNA-497 and its prognostic significance in human breast cancer. Diagn Pathol 2013, 8(1):172-178.

29. Varley J, Brammar W, Lane D, Swallow J, Dolan C, Walker R: Loss of chromosome $17 \mathrm{p} 13$ sequences and mutation of p53 in human breast carcinomas. Oncogene 1991, 6:413-421.

30. Eyfjörd JE, Thorlacius S, Steinarsdottir M, Valgardsdottir R, Ogmundsdottir HM, Anamthawat-Jonsson K: p53 abnormalities and genomic instability in primary human breast carcinomas. Cancer Res 1995, 55:646-651.

31. Gursan N, Karakök M, Sari I, Gursan MS: The relationship between expression of $\mathrm{p} 53 / \mathrm{Bcl}-2$ and histopathological criteria in breast invasive ductal carcinomas. Int J Clin Pract 2001, 55:589-590.

32. Pratap $R$, Shousha S: Breast carcinoma in women under the age of 50 : Relationship between p53 immunostaining, tumour grade, and axillary lymph node status. Breast Cancer Res Treat 1998, 49:35-39.

33. Nag S, Qin J, Srivenugopal KS, Wang M, Zhang R: The MDM2-p53 pathway revisited. PLoS One 2013, 27(4):254-271.

34. McCann AH, Kirley A, Carney DN, Corbally N, Magee HM, Keating G, Dervan PA: Amplification of the MDM2 gene in human breast cancer and its association with MDM2 and p53 protein status. Br J Cancer 1995, 71:981-985.

35. Deb SP: Cell cycle regulatory functions of the human oncoprotein MDM2. Mol Cancer Res 2003, 1:1009-1016.

36. Knappskog S, Lønning PE: P53 and its molecular basis to chemoresistance in breast cancer. Expert Opin Ther Targets 2012, 16(Suppl 1):S23-S30.

37. Marine JC, Dyer MA, Jochemsen AG: MDMX: from bench to bedside. J Cell Sci 2007, 20:371-378.

38. Migliorini D, Lazzerini Denchi E, Danovi D, Jochemsen A, Capillo M, Gobbi A Helin K, Pelicci PG, Marine JC: Mdm4 (Mdmx) regulates p53-induced growth arrest and neuronal cell death during early embryonic mouse development. Mol Cell Biol 2002, 22:5527-5538.

39. Matijasevic Z, Krzywicka-Racka A, Sluder G, Jones SN: MdmX regulates transformation and chromosomal stability in p53-deficient cells. Cell Cycle 2008, 7:2967-2973

doi:10.1186/1746-1596-9-71

Cite this article as: Yu et al:: Amplification of Mdmx and overexpression of MDM2 contribute to mammary carcinogenesis by substituting for p53 mutations. Diagnostic Pathology 2014 9:71.

\section{Submit your next manuscript to BioMed Central and take full advantage of:}

- Convenient online submission

- Thorough peer review

- No space constraints or color figure charges

- Immediate publication on acceptance

- Inclusion in PubMed, CAS, Scopus and Google Scholar

- Research which is freely available for redistribution

Submit your manuscript at www.biomedcentral.com/submit
C BioMed Central 